\title{
Urgences
}

\section{David Lonergan, Les otages, Rimouski, Éditeq, 1987, 100 p. Hélène Chassé}

Numéro 19, janvier 1988

Le tour du texte

URI : https://id.erudit.org/iderudit/025454ar

DOI : https://doi.org/10.7202/025454ar

Aller au sommaire du numéro

Éditeur(s)

Urgences

ISSN

0226-9554 (imprimé)

1927-3924 (numérique)

Découvrir la revue

Citer ce compte rendu

Chassé, H. (1988). Compte rendu de [David Lonergan, Les otages, Rimouski, Éditeq, 1987, 100 p.] Urgences, (19), 108-110. https://doi.org/10.7202/025454ar

Ce document est protégé par la loi sur le droit d'auteur. L’utilisation des services d’Érudit (y compris la reproduction) est assujettie à sa politique d'utilisation que vous pouvez consulter en ligne.

https://apropos.erudit.org/fr/usagers/politique-dutilisation/
Cet article est diffusé et préservé par Érudit.

Érudit est un consortium interuniversitaire sans but lucratif composé de l’Université de Montréal, l'Université Laval et l'Université du Québec à Montréal. Il a pour mission la promotion et la valorisation de la recherche. https://www.erudit.org/fr/ 


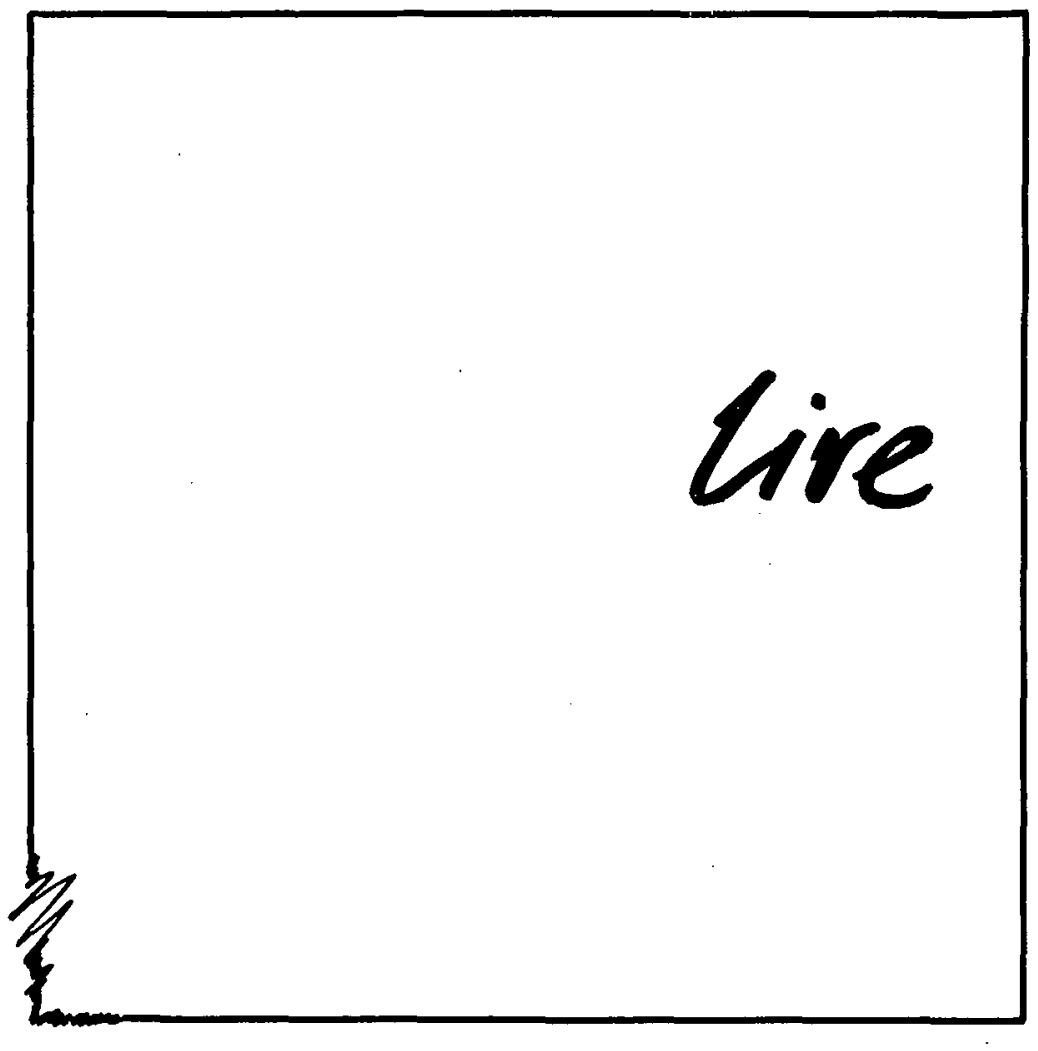




\section{David Lonergan: Les otages, Rimouski, Éditeq, 1987, 100 p. Prix littéraire des Associés 1987.}

L'an dernier, le rideau se levait sur ce seul concours littéraire réservé aux écrivains et écrivaines de l'Est du Québec. Enfin, une belle initiative qui donne aux rêves un certain poids d'espérance...

Sur ce territoire, on le sait, les pensées volent et des milliers de pages se noircissent... Mais quelles possibilités d'être lu/e, publié/e?

Parmi les manuscrits soumis au concours de cette année, plusieurs ont attiré l'attention des membres du jury. Quelques-uns l'ont retenue. Un seul, dit-on, l'a satisfaite au point d'éliminer toute velléité de confrontation. Par une très forte longueur d'avance, la dramatique de David Lonergan ralliait tous les suffrages.

Nous nous sommes vite précipitée sur l'objet d'une si rare harmonie critique.

- C'est un hold-up! Hands up! Les mains en l'air!

Première constatation heureuse. Voici une pièce en un acte, divisée en treize scènes, qui soutient le genre difficile auquel elle prétend appartenir: la comédie satirique. La mélancolie, la tendresse, un certain sublime dans l'absurde des situations atténuent l'agressivité véhiculée dans les nombreuses dénonciations.

Joutant de verve avec les mentalités et les âges, laction se déroule dans le village fictif de Sainte-Claire-de-la-Baie, en Gaspésie. Il pourrait s'agir, en fait, de n'importe quel village "réel» de là-bas:

- C'est ça, pis après on passe pour des sauvages parce qu'on jase avec les touristes. Faut avoir de l'entregent... (sic) Astheure qu'ils se mettent à couper dans nos permis de pêche, va falloir qu'on en ait en sifflet de baleine de l'entregent. Parce qu'il faut se la fermer en plus... (Georges Bernatchez, 61 ans, pêcheur, chômeur et maire scène 2, p. 18).

Endroit où il est préférable davoir rapidement saisi que:

- ... il y a des choses qui valait mieux faire par en dessous... (Martine Labrie, 25 ans, assistée sociale - scène 9, p. 61).

Où les promesses électorales sont des somnifères puissants, où l'attente dure depuis des générations, où «tout ce qui reste, c'est un 
chèque de chômage». Mais où, quand même:

- Jamais je ne quitterai le village!... (Emmy Labrie, 60 ans, propriétaire d'un vieux commerce délabré et déserté - scène 6. p. 41).

Où, somme toute:

- Les journalistes viennent en Gaspésie quand il y a une gang qui fait sauter de quoi... quand il va y avoir un cadavre à photographier (scène 11).

Donc:

- Si ça pogne chez Kadhafi... on n'est pas plus niaiseux qu'eux autres pis on n'est certainement pas mieux emmanchés!... (Georges, scène 12; p. 88).

Ainsi, mis en branle par un jeune immigré du "haut" (Louis Daberllay, Suisse d'origine, spécialisé dans la construction dabris nucléaires - chômeur au Québec, il va sans dire ) qui descend en Gaspésie pour commettre un délit au hasard, dans le seul but de se faire arrêter et de pouvoir dénoncer la stupidité du système parce qu'il n'a plus les moyens de payer sa "liberté", naitra dans le magasin général d'Emmy Labrie le FLJS, le Front de Libération des Jeunes et des Sous-développés, mouvement terroriste de Sainte-Claire-de-laBaie.

Même conduit habilement à son extravagance, le discours rejoint, de prime abord, celui dont tant de nos «auteurs engagés», particulièrement au théâtre, ont usé et abusé.

Mais... David Lonergan a trop d'expérience, trop de finesse et d'art de la parole pour n'avoir pas su utiliser ce piège.

Premier tour de manivelle. Fusil de chasse et pistolet à eau. Film de cowboy des frères Marx, de James Bond et de Bruce Lee. Tout le monde en place. C'est parti!

— C'est un hold-up! Hands up! Les mains en l'air!

Deuxième constatation, encore plus heureuse que la précédente. Les otages, c'est d'abord le produit d'un "pratiquant" du théâtre qui exploite jusqu'au délire les ficelles du métier. Dans sa mise en scène sur papier (didascalies) comme dans le chassé-croisé de ses dialogues, il n'oublie pas un instant le rapport devant s'établir entre les spectateurs et le spectacle. 
S'inspirant à la fois de la Farce de Maistre Pathelin (le voleur volé - ici, dans son idée!), du «panique» d'Arrabal, du parodique d'un Frisch ou d'un Dürrenmatt, David Lonergan invente sa propre stratégie de l'absurde.

Il ne renonce en rien au mimétisme langagier ou gestuel. L'intrigue et les personnages sont clairement définis. C'est dans le traitement psychologique et idéologique quil allie le loufoque au sous-tendu tragique du message.

De cette façon se crée l'illusion (même en simple lecture) d'un univers qui n'a rien de fictionnel mais qui, cherchant à déclencher le rire par des revirements inattendus, des changements de rythme, des hasards (quelquefois hasardeux, avouons-le...), débouche (horstexte) sur la réflexion universelle apportée par les «dingues du nonsense». Liberté, pouvoirs de l'homme diminués, exposés, dégradés.

\section{- C'est un hold-up! Hands up! Les mains en l'air!}

Cette intimation marque le début et la fin des Otages de David Lonergan. Théorie du cercle qui se ressoude? Une "humeur" s'est infiltrée dans la brisure provoquée par l'auteur. Une tornade a soufflé. La conscientisation des personnages ne s'est pas faite seulement par le biais d'une ironie événementielle, elle leur a permis une révolte oblique, burlesque et vivifiante.

Avec sa tête de vengeur angélique, David Lonergan a su faire de la comédie satirique moderne ce que probablement elle devrait être: l'envers fou de l'utopie.

Hélène Chassé

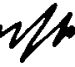

\section{Denis Bégin (avec la collaboration de Richard Perreault): La chanson québécoise, Cap-de-la-Madeleine, Ed. du Réseau U, 1987, 354 p.}

\section{LA CHANSON QUEEBEECOISE EN CLASSE: ORDI- NAIRE}

En 1979, Denis Bégin a présenté à l'Université de Sherbrooke une thèse de doctorat intitulée Introduction de la chanson québécoise dans l'enseignement littéraire au cours secondaire. Sa ré- 